Revista Iberoamericana, Vol. LXXVI, Núm. 231, Abril-Junio 2010, 459-475

\title{
EN TORNO AL GÉNERO NEGRO: ¿LA DISOLUCIÓN DE UNA CONCIENCIA ÉTICA O LA RECUPERACIÓN DE UN NUEVO COMPROMISO POLÍTICO?
}

\author{
POR \\ H. Rosi Song \\ Bryn Mawr College \\ Lo importante es saber contar la historia \\ de lo que se ha perdido, de Bergai, de las cartas, \\ así vuelven a vivir. \\ Carmen Martín Gaite, El cuarto de atrás (1979)
}

El interés por el género negro une, a primera vista, la práctica literaria y crítica del autor cubano Leonardo Padura Fuentes (1955) y la del escritor español Manuel Vázquez Montalbán (1939-2003). Estos autores no sólo han reflexionado sobre sus diferentes posibilidades estéticas, como lo testimonian los numerosos trabajos ensayísticos sobre el tema, sino que también se han servido mutuamente como modelo de la capacidad crítica de este género literario. Para Padura, por ejemplo, el escritor español ha sido una constante referencia en su aproximación crítica a este género. ${ }^{1}$ Por su parte, Vázquez Montalbán había identificado las novelas negras del autor cubano como ejemplo de una literatura que supera la identificación revolucionaria y es capaz de criticar sus realidades sociales ( $Y$ Dios 359). Este común interés presenta, asimismo, un punto de encuentro en la relación que ambos escritores establecen entre la práctica del género negro y en la crítica de una ideología política a fin de insistir y volver sobre sus principios éticos.

Vázquez Montalbán, formado intelectual y personalmente bajo el franquismo, fue conocido por su participación en la oposición contra la dictadura y su vinculación -si bien irregular- con el partido comunista español. Su simpatía por las causas abogadas por este partido estuvo siempre presente a pesar de los desencuentros que tuvo con su expresión política, los cuales fueron duramente criticados a lo largo de su larga producción intelectual. Esta férrea convicción izquierdista se tradujo en una persistente mirada evaluadora y, hasta cierto punto, frustrada hacia la realidad

1 Véase su estudio, Modernidad, posmodernidad y novela policial (2000) además de su entrevista en la revista Quimera (1991). 
política española, motivándolo a enfocarse en las razones por las cuales estos ideales políticos nunca llegaron a plasmarse durante su transición hacia la democracia. Este sentimiento de frustración se repite, de cierta manera, en la obra de Padura, producto intelectual y cultural de la Revolución Cubana y quien ha vivido la limitada realidad de sus ideales. A pesar de la distancia geográfica y generacional, además de las diferentes circunstancias que les ha tocado vivir, a ambos los une la negativa a renunciar al proyecto social que propusiera el marxismo y la dura crítica de su práctica política encarnada en regímenes totalitarios y en el sufrimiento de la población civil. Esta resistencia los impulsa a revisar el pasado para recuperar la memoria de sus errores que, al mismo tiempo, plantea la necesidad de una imaginación para el futuro. A través del análisis de sus últimas novelas, El hombre de mi vida (2000), de Vázquez Montalbán y La neblina del ayer (2005), de Padura, este ensayo explora esta resistencia enfocándose en la incapacidad de sus personajes principales, el detective Pepe Carvalho y el ex policía Mario Conde, respectivamente, de superar el pasado. En estas obras, el pasado se vuelve persistente, como un fantasma que no puede dejar de rondar aquellos sitios previamente ocupados, y que se materializa en el espacio urbano que recorren melancólicamente estos investigadores rastreando sus pérdidas, sus memorias y, finalmente, la posibilidad de un porvenir. Como se argumenta en este trabajo a través de una discusión entre la compatibilidad de la estética posmoderna, su posicionamiento ético y el género negro, en las novelas de estos autores se manifiesta una lectura del pasado que insiste en la necesidad de una conciencia política que, a pesar de los fracasos y las nuevas etimologías, sigue favoreciendo una ideología de izquierdas. ${ }^{2}$

Si la novela negra española se ha leído como una innovación narrativa del posfranquismo que intentó capturar la realidad social, cultural y política de la transición; ${ }^{3}$ el fenómeno de la novela policial cubana parte de un programa del Estado que aspiró a fomentar novelas que apoyaran los fines del gobierno revolucionario. El detective privado que desde el margen de la sociedad capitalista revela su corrupción y sus crímenes se convierte en el contexto socialista en miembro del cuerpo de policía y parte del sistema. Desde esta posición, trabaja

2 Por ejemplo, lo que le interesa a Vázquez Montalbán es un nuevo humanismo, que si bien fue una noción criticada por él mismo anteriormente, le parece la única alternativa frente a la "lógica ciega de carácter mecánico y determinista, que ignora la supervivencia humana, y al hombre como individuo...” (Tyras 33). Este humanismo sigue relacionado a un principio ético favorecido desde una política de izquierdas.

3 El auge de la novela negra en España, asociada con el fenómeno del desencanto, se acepta como parte de una nueva narrativa que empezó a estar en boga a partir del final del franquismo. Según José F. Colmeiro, este género explora los conflictos y las contradicciones de una época de cambio y confusión que responde a una crisis del sistema social y los cambios políticos por los cuales está pasando el país (263).

Revista Iberoamericana, Vol. LXXVI, Núm. 231, Abril-Junio 2010, 459-475
ISSN 0034-9631 (Impreso) 2154-4794 (Electrónico) 
en colaboración con el Estado para mantener el orden y proteger la sociedad de influencias contrarrevolucionarias que puedan surgir internamente o infiltrarse desde el exterior. El estímulo inicial, en forma de un concurso organizado por el Ministerio del Interior, buscaba premiar una novela policial cubana que contribuyera a la prevención de "actividades contrarrevolucionarias y delictivas antisociales”(Menton 914). Padura redacta su primera novela policíaca como reacción ante el exceso de este modelo narrativo que, en su cumplimiento de los parámetros establecidos para el género por el gobierno socialista, pronto se agota y no puede sino ofrecer una visión maniqueísta de la realidad (Epple 56-57). ${ }^{4}$ Lo que rechaza el escritor cubano es el estricto condicionamiento ideológico de la creación artística, interesándose en los "matices" de la literatura y que, en el caso de Cuba, pueden reflejar su dura realidad (Epple 66). La novela policíaca que escribe Padura le permite revelar los lados oscuros de la realidad social, pero también contar una historia del pasado, buscando las razones que determinan el presente (Smith 70).

Este interés por la realidad circundante y la investigación de sus condiciones es también lo que atrajo a Vázquez Montalbán al género negro. Reflexionando sobre sus primeros pasos dentro del género, el autor reconoció sobre todo la posibilidad estratégica que le proveía este modelo narrativo, que tenía como referente la novela dura norteamericana. Como crónica de una sociedad compleja, conflictiva, competitiva y urbana, su obra/su narrativa describía una sociedad que se parecía a la española, "abocada al delirio neocapitalista y parademocrático, dependiente de la doble verdad, la doble moral y la doble contabilidad del capitalismo avanzado" (Vázquez Montalbán, La literatura 145). El escritor fundamentó supráctica narrativa como una novela crónica que se presta de la novela negra tres elementos: el punto de vista; el elemento técnico de la investigación, basada en la encuesta, y un elemento poético. Lo que adoptó fue la realidad vista por un merodeador social, un flâneur moderno, cuya función, para Vázquez Montalbán, habría sido el "husmear las huellas de la sociedad de desperdicio" y la poética de una nueva moralidad que replanteaba el “'no matarás’ como violación del código de cohabitación productiva y reproductiva vigilado por el estado, el único que puede matar” (La literatura 145).

Más allá de lo estético, la novela negra sigue los parámetros de la posmodernidad al cuestionar la representación de la realidad a través del discurso literario o histórico, presentando un texto reflexivo, consciente de su propio proceso de construcción y la naturaleza ficticia de su discurso. Este proceso de concienciación revela, asimismo, la problemática relación que existe entre la estética posmoderna y la representación del pasado. Según Linda Hutcheon, el tratamiento de la Historia desde la perspectiva

4 La novela que escribe es Pasado perfecto y es con la que participa en el concurso del Ministerio del Interior en 1991. Aunque luego se entera de que el jurado le había otorgado el premio, el premio se declara desierto porque su novela “no cumplía las expectativas ideológicas en uso” (Epple 57).

Revista Iberoamericana, Vol. LXXVI, Núm. 231, Abril-Junio 2010, 459-475
ISSN 2154-4794 (Electrónico) 
posmoderna demuestra que el pasado es algo que se puede acceder solamente a través de sus rastros. Lo que nos queda en el presente son sus representaciones y únicamente a partir de ellas podemos construir nuestras narrativas o explicaciones sobre el pasado (Hutcheon 58). Lo que se recalca en este proceso, por lo tanto, es que la representación de la Historia se convierte en la historia de la representación revelando un deseo por entender el presente cultural como producto de sus previas representaciones (58). La noción de conocer el pasado únicamente a través de sus representaciones niega la posibilidad de la existencia de una versión que asuma o sea capaz de transmitir una cierta autoridad, lo cual, al final, acaba renunciando a su propia comprensibilidad. No extraña, por lo tanto, que Jameson se refiera a la posmodernidad como un esfuerzo por pensar el presente históricamente en una edad en la que se ha olvidado en cómo pensar históricamente (ix). Como observa este pensador, en lo posmoderno no sólo el pasado en sí ha desaparecido sino también lo que se conoce como " "sense of the past' or historicity and collective memory" (309).

Es desde esta posición que Vázquez Montalbán había insistido en que su afición a la estética posmoderna no se confundiera con la interpretación reaccionaria que ha reducido la posición crítica de ésta a la del rechazo y la superación de la Historia. El fin de la historia como diagnóstico de la posmodernidad es uno perverso y fácilmente debatible según el autor, ya que "es evidente que la historia no se resigna a acabar, que sigue, y la dialéctica también” (Tyras 166). Distinguir entre la adopción de una innovación de códigos lingüísticos y el posicionamiento ético ante la historia resulta crucial para este escritor, quien no asume una "posmodernidad ahistórica" sino que plantea la necesidad de "re-historificar la posmodernidad" que posibilite el cambio histórico así como el futuro. Para Vázquez Montalbán, el presente que consagra la posmodernidad está paralizado, totalmente abandonado y que es, al final, la ofensiva de una ideología reaccionaria. Ésta nos obliga a aceptar una historia que se fundamenta en hechos acabados, insistiendo en la inutilidad de pensar en el pasado así como en la memoria histórica e insistiendo en que "pensar en el pasado es tan inútil como pensar que el futuro puede ser diferente”, proponiendo, a la misma vez, la ilusoria posibilidad de "apostar por un futuro basado en la negación del presente” (Tyras 167). Al final, lo que se rechaza en las novelas negras del escritor español, así como en su contraparte cubana, es la idea de enfrentarse al pasado como algo consumado, insistiendo en la importancia de la función social que puede cumplir la literatura para luchar en contra de la desesperanza social y política del presente, sintomática de esta visión histórica (Epple 60-61).

La desazón que expresa Padura debe leerse en relación a la actitud que prevalece en el presente acerca de las afiliaciones que quedan de la experiencia histórica del socialismo y una ideología de izquierdas. El mismo Vázquez Montalbán revelaba que su producción intelectual estaba profundamente marcada por una obsesión: Revista Iberoamericana, Vol. LXXVI, Núm. 231, Abril-Junio 2010, 459-475
ISSN 2154-4794 (Electrónico) 
la de la gran desilusión derivada del fracaso del Mayo de 68 (Tyras 54, 76). La derrota y crisis de la política de izquierdas, acompañada de una posmodernidad reaccionaria, ha condicionado nuestro entendimiento de esta historia y su lucha social. Como apunta Edward Soja, en nuestra época, el socialismo se ha transformado en el discurso público, hasta cierto punto, en sinónimo de totalitarismo o un lastimosamente anticuado idealismo que encarna una posición de permanente derrota (123). ${ }^{5}$ Jameson denuncia esta postura rechazando la declaración de que el posmodernismo marca el final de la ideología cuando ésta se utiliza como referente de la derrota del marxismo y, en ese sentido, con la noción de la pérdida de la utopía (159). Lo que formula Jameson es una nueva lectura de este empeño a través de una interpretación crítica que reconoce una nueva organización espacial hacia la que han girado las relaciones sociales y las instituciones políticas (160). Lo importante no es la producción de este espacio sino el "concepto" de tal espacio (165). Desde esta perspectiva, el agotamiento de esta noción de la ideología debe garantizar la articulación de nuevas formas críticas que permitan no sólo una mejor comprensión de nuestra realidad, sino también la recuperación de un instinto utópico.

Las novelas negras de Vázquez Montalbán y Padura plantean una lectura del pasado que transforma nuestra aproximación a la relación entre lo social y lo político a través de su materialización en el espacio urbano. Por un lado, la obra intelectual del escritor español puede leerse como un obsesivo “inventario de déficits" que puede entenderse como la denuncia de la pérdida de una visión utópica de la realidad (Tyras 206). De la misma manera, Padura explora insistentemente el abandono sufrido por la población civil en la lucha por la Revolución. En las palabras del escritor que recoge Pérez Miguel en su artículo, lo que hace su obra es dar "constancia de que hay un sueño que dejó de existir, de que las esperanzas han desaparecido” ('En Cuba...'). Si la mirada hacia el pasado que ofrece el cubano en sus novelas "refleja la desesperanza social y política del presente... donde están ocurriendo cosas que nos rebasan a todos como individuos", dos elementos constantes en la obra del español son la melancolía provocada por una frustración histórica y una nostalgia que intenta recordar el pasado (Epple 61; Tyras 54, 130). Esta aparente negatividad cumple la función de trazar una pérdida y los síntomas de esta carencia en el presente. Es decir, la configuración de estos "déficits” se desarrolla dentro del marco urbano

5 Soja articula claramente esta transformación discursiva tomando como ejemplo el panorama político y cultural de los EE.UU.: "radical feminism has been made to look biologically aberrant and inherently destructive of the most cherished features of the human family, radical environmentalists and antinuclear activists are represented as foolish or demented Luddites, the American liberal democrat is made into a an anachronistic oaf fumbling away the country's wealth, postcolonial liberation movements are reduced to the lunacy of primitive despots selfishly enraged at their backwardness, affirmative action becomes reverse racism hidden behind the veils of left-wing political correctness, poverty is equated with laziness, and so on” (123).

Revista Iberoamericana, Vol. LXXVI, Núm. 231, Abril-Junio 2010, 459-475
ISSN 2154-4794 (Electrónico) 
que recorren los personajes literarios de estos dos escritores recuperando el pasado que produce su tejido social. Así, Barcelona para Pepe Carvalho y La Habana para Mario Conde se erigen como lugares privilegiados para trazar estas pérdidas ya que, según Vázquez Montalbán, la ciudad es el "lugar donde [uno] ha educado sus actos reflejo, donde ha podido medir las distancias, la relación con los otros, donde ha marcado un territorio propio y que luego lo ha ido ampliando en función del conocimiento adquirido” (Tyras 37). Estos espacios, por lo tanto, funcionan como mapas cognitivos o cartografías ideológicas que retienen, identifican y conectan la memoria del pasado y sus ruinas con el presente.

El hombre de mi vida es la última novela de la Serie Carvalho, donde el detective se reúne con uno de los personajes que había aparecido en una de sus primeras novelas negras Los mares del Sur (1979). ${ }^{6}$ La hija del empresario asesinado cuya muerte investigó Carvalho hace ya más de dos décadas, Jessica Stuart-Pedrell o Yes, regresa a Barcelona antes del comienzo del segundo milenio después de haberse marchado de la ciudad a recorrer el mundo tal como le había aconsejado el investigador. Mientras se desarrolla el reencuentro entre Carvalho y Yes, también retorna a la ciudad la antigua novia del primero, Charo, quien se había marchado a Andorra hacía siete años en El laberinto griego (1991). Estos reencuentros con el pasado suceden a la par de la investigación de la muerte de un joven homosexual involucrado con el líder de una secta religiosa. Cuando el detective está ultimando los detalles del caso, el amante de Charo lo contrata para trabajar en un nuevo proyecto en defensa de Cataluña y su futuro como nación sin estado, forzando la investigación hacia un rumbo inesperado. Al final, el proyecto se revela como una corrupta lucha de poder que tiene conexiones con el crimen que investiga Carvalho, prematuramente resuelto al inicio de la novela, y que lo lleva a reevaluar su pasado mientras recorre la irreconociblemente transformada ciudad de Barcelona.

Después de catorce años desde que dejara el cuerpo de policía, nos encontramos con el ex teniente investigador Mario Conde en la última novela de Leonardo Padura. Completada la tetralogía "Las cuatro estaciones” en 1998, Padura regresa al género negro con una novela donde vemos a Conde recorriendo las calles de La Habana comprando y vendiendo libros viejos. ${ }^{7}$ En La neblina del ayer, Conde se

\footnotetext{
6 Si bien la aventura de Carvalho continúa al final de esta novela cuando el detective, acompañado de su ayudante Biscuter, emprende un viaje alrededor del mundo en los dos tomos de Milenio Carvalho, la trama de estas aventuras supera los límites del género negro. Desde esa perspectiva, es posible asumir el final de la serie Carvalho con esta novela. Además, como el mismo autor reconoce, en Milenio, el personaje principal ya no es el detective, sino Biscuter (Tyras 110).

7 Los títulos que componen la tetralogía son Pasado perfecto (1991), Vientos de cuaresma (1994), Máscaras (1995) y Paisaje de otoño (1998). Por otra parte, el nuevo oficio de Conde lo conocemos por Adiós Hemingway \& La cola de la serpiente, un libro de dos cortos relatos que publica Padura en Cuba en el 2001.
}

Revista Iberoamericana, Vol. LXXVI, Núm. 231, Abril-Junio 2010, 459-475
ISSN 2154-4794 (Electrónico) 
encuentra con una biblioteca construida antes de la Revolución que contiene los tomos más valiosos e importantes de la historia cultural de Cuba y, entre las páginas de uno de ellos, una nota periodística junto a la fotografía de una misteriosa cantante de boleros. Los encargados de cuidar estos tesoros, agotados por las dificultades económicas, deciden venderlos después de haber esperado más de tres décadas el retorno de los herederos de su dueño, el señor Alcides Montes de Oca. Conde, el primero en ver esta colección, adivina que una vez iniciada la venta, los libros pronto entrarían en el mercado negro privando al país de conservar su patrimonio cultural. Una vez que convence a los hermanos encargados de la colección que les deje ayudar, uno de ellos aparece muerto y el ex policía se convierte en sospechoso del crimen. Bajo el escrutinio de su antiguo amigo y ayudante, el ahora capitán Manuel Palacios, Conde intenta resolver el crimen mientras trata de satisfacer su curiosidad sobre el paradero de Violeta del Río, la cantante de boleros que ha desaparecido sin dejar rastros. La obra refleja esta doble búsqueda intercalando la historia de la pesquisa con una serie de cartas anónimas que hablan de una relación de amor, y cuya conexión con la biblioteca, los hermanos y el fantasma de una cantante de boleros, es lo que dilucida Conde en su recorrido por los lugares más olvidados de la capital cubana.

La importancia del concepto del espacio urbano articulado por Lefebvre, según explica Jameson, es que nos ofrece una nueva forma de imaginación espacial, capaz de confrontarse al pasado de manera innovadora y de leer sus menos tangibles secretos del patrón de sus estructuras espaciales -cuerpo, cosmos, ciudad-, ya que todos ellos marcan las más intangibles organizaciones de la economía cultural y la libidinal (365). Es decir, el espacio urbano se presenta como producto social cuyo estudio demuestra un espacio ideológico que funciona como "a tool of thought and of action; that in addition to being a means of production it is also a means of control, and hence of domination, or power" (Lefebvre 26). Pero para poder comprender la lógica de este mecanismo, Jameson argumenta que es necesario revisar la noción del espacio desde la teoría del posmodernismo, ya que desde ella queda claro cómo nuestro período -el del capitalismo tardío- se ha especializado de manera única, de tal forma que para nosotros el espacio es un dominante modelo existencial y cultural (365). Si el modernismo puede entenderse como la experiencia incompleta del proceso de la modernización puesto que las contradicciones entre el mundo rural y el moderno coexisten temporalmente, posibilitando una referencia (o memoria) mutua, la posmodernidad indica una época en la que este desarrollo se ha superado y ha logrado implementar su propia lógica (Jameson 366). El argumento que formula Jameson es que el espacio y el tiempo en la posmodernidad no son factores naturales sino que ambos son "consequence and projected afterimages of a certain state or structure of production and appropriation, of the social

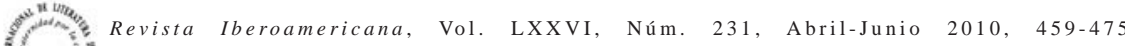
ISSN 0034-9631 (Impreso) ISSN 2154-4794 (Electrónico)
} 
organization of productivity” (367). Esta situación implica que la recuperación del pasado requiere una estrategia diferente en la posmodernidad por su inhabilidad de recobrar un referente original. ${ }^{8}$ Para este teórico, por lo tanto, esta incapacidad explica el tratamiento de la historia desde la estética (y la teoría) posmoderna, desde la historiografía fantástica ("fantastic historiography”) que comunica una libertad creativa ante la imposibilidad de control ("agency here steps out of the historical record itself into the process of devising it”) hasta la historiografía espacial ("spatial historiography") que nos puede ayudar a entender lo sucedido con el espacio en la posmodernidad y el sentido de la historia (368-70). La operación espacial que realiza el posmodernismo no es trazar la ruptura de un preexistente y antiguo orden totalitario sino la emergencia de lo múltiple de maneras nuevas e inesperadas, de eventos no relacionados y de tipos de discursos, que constituye en una diferenciación y especialización de la realidad, “[d]ifferent moments in historical or existential time are here simply filed in different places" (Jameson 372-73). Ante la aparente incompatibilidad de los eventos, Jameson utiliza el ejemplo de la lectura del periódico en la cual, a pesar de la aparente desconexión que existe entre una columna y otra de noticias, el lector es capaz, a través de una operación espacial que recalca sus yuxtaposiciones paradójicas, de vislumbrar finalmente sus conexiones. Es este ejercicio de espacialización es lo que puede entenderse, dentro de la posmodernidad, como un pensamiento histórico o el análisis de la realidad que permite "the ocasional flash of historical understanding" (374).

Desde este punto de vista, la trayectoria urbana que trazan los investigadores de las novelas de Vázquez Montalbán y Padura, en el proceso de la resolución del crimen que acaba uniendo y posicionando sus más inconexos y desorientadores componentes, puede entenderse como una "espacialización” de la historia que, además de iluminar un trasfondo previamente desapercibido brinda un breve momento de comprensión y reconocimiento. De esta manera, la Barceloneta a la que se enfrenta Carvalho expone las contradicciones de la Villa Olímpica (a través de su visualización espacial); mientras que la pesquisa de Conde desvela los sectores que se van transformando bajo la dolarización de la economía cubana en tanto que otros permanecen terminantemente olvidados, tanto por la Revolución como por el capitalismo emergente de la Isla. Este recorrido que traza el espacio urbano de ambas ciudades conectando sus diferentes puntos y el entramado de su pasado es lo que Jameson describiría como una solución que "lights up like a nodal circuit in a slot machine” (374) y que al final vislumbra una organización espacial que intenta borrar la historia y la memoria de sus instituciones políticas y sus relaciones sociales.

8 Esta incapacidad se puede relacionar a la noción de la pérdida de la historia asociada con el posmodernismo. Como observa Nichols, esta pérdida también queda acompañada “por la pérdida de espacio que suplanta la ideología tanto como el pasado según la lógica del capital” (190). Revista Iberoamericana, Vol. LXXVI, Núm. 231, Abril-Junio 2010, 459-475
ISSN 2154-4794 (Electrónico) 
De manera similar, William Nichols ha analizado el espacio urbano que aparece en la Serie Carvalho de Vázquez Montalbán a través del concepto de "thirdspace" de Edward Soja, en el cual el detective es capaz de leer la ciudad no solamente como parte de la escenificación de su investigación, sino como “una interacción simultánea de ideología, historia y subjetividad colectiva además de individual” (15). ${ }^{9}$ En el caso de la novela de Padura, La Habana que se traza a través del recorrido de Conde es el espacio urbano donde se revela la fragmentación ideológica y social del país, "which seems to have lost the heart of its ideology; and which is patently selling itself back into a colonial condition" (Braham 56).

Lo que emerge de este nuevo espacio (o de esta operación espacial) es, al final, la supresión de la distancia y la saturación despiadada de cualquier vacío o espacios desocupados, de manera que el cuerpo posmoderno, transite por donde transite, "is now exposed to a perceptual barrage of immediacy from which all sheltering layers and intervening mediations have been removed" (Jameson 413). Este espacio saturado es para Jameson síntoma y expresión de un nuevo y original dilema histórico, que tiene que ver con nuestra inserción como sujetos individuales dentro de una serie de realidades multidimensionales y radicalmente discontinuas, cuyas estructuras van desde los espacios privados de la burguesía hasta el más inimaginable descentramiento del mismo capital global (413). La condición del individuo ante esta disyuntiva, entre la imposibilidad de aprehender una totalidad y la capacidad limitada de conectar con una serie interminable de realidades diferenciadas y especializadas, se manifiesta en las novelas negras de Vázquez Montalbán y Padura a través de un estado afectivo que permea las pesquisas de sus investigadores. Tanto en las novelas que ocupan este ensayo como en las otras que componen la Serie Carvalho o la tetralogía "Las cuatro estaciones", lo que se revela es el rastro, ya sea físico o emocional, de una pérdida que se hace patente a través de la melancolía que tiñe el recorrido de Carvalho y el Conde por sus ciudades. Enfrentada a lo que podemos identificar como la crisis del referente (o su pérdida) elucidada desde la teoría posmoderna, la melancolía se presenta como un concepto dialéctico capaz de iluminar los límites de la misma noción del “object-relation,” que no trata de la privación del objeto sino de la imposibilidad de tal relación y que, trascendiendo la lectura psicoanalítica, puede ofrecer una herramienta crítica en relación a la noción de la pérdida y la memoria (Pensky 26-27). La melancolía, estrechamente unida a la idea de la pérdida, está también profundamente afectada por la memoria, ya que el acceso entre una y otra se complementan y se sustituyen. Para Max Pensky,

9 Como explica Nichols, Soja parte de la teoría de la espacialidad de Lefebvre para articular el concepto de "thirdspace" que reestructura ontológicamente nuestra forma "de ver, interpretar y leer el texto espacial”, con un escepticismo radical a todo lo establecido (187).

ISSN 0034-9631 (Impreso) 
es Walter Benjamin quien intenta revelar la fuerza dialéctica de la melancolía como una fuerza crítica desde su dimensión subjetiva en relación al objeto de su atención, "a discourse about knowledge, about the urge toward the acquisition and articulation of a privileged insight into the world," un conocimiento que se vuelve accesible para aquel sujeto contemplativo (22). Benjamin ubica la posibilidad de entender el pasado en esta contemplación melancólica, la Historia como "subject of a structure whose site is not homogenous, empty time, but time filled by the presence of the now" (261). ${ }^{10}$ Este presente que no está en transición, en el cual el tiempo se detiene y está parado, es irremplazable para una comprensión que busca “a unique experience with the past” (Benjamin 262). Como bien indica Idelber Avelar, desde este punto de vista, la historia está inevitablemente espacializada, solamente redimida en un gesto helado capaz de capturar el pasado como una mónada alegórica, y esta relación de amparo con la memoria que debe petrificar el pasado como una imagen y aislarla de todas sus asociaciones protectoras se debe a Benjamin, quien había concebido la memoria no como un instrumento para explorar el pasado sino como su teatro donde ese pasado se materializa (10). Es así como la escenificación del pasado, mediada por la melancolía que recupera su memoria, traza sus ruinas allí donde los vestigios del pasado se representan en un destello que conlleva el carácter intuitivo de una iluminación momentánea (Benjamin 255).

La Barcelona que explora el personaje de Vázquez Montalbán es el producto de una reconstrucción urbana que se inicia dentro del proyecto socialista de la transición. Lo que queda patente de este espacio es el abandono de los principios éticos del socialismo a favor de la especulación urbana (McNeill 36). Víctima del llamado "capitalismo salvaje", la ciudad que se despliega ante Carvalho es un parque de atracciones, cuya edificación según las demandas y los deseos del capital lo convierte "en una gran operación de marketing bajo la máscara de armonía internacional” (Nichols 1). El detective, quien en sus previas pesquisas había recorrido la ciudad con un conocimiento amplio y vital a través del cual se vislumbran sus más guardados secretos, se encuentra ante un espacio desorientador que es incapaz de procesar. Balibrea-Enríquez lee las primeras novelas negras de Vázquez Montalbán como una forma de utilizar la estructura de la narrativa del género negro en desafío y como trasgresión del status quo, la narración es el vehículo de clarificación que ofrece la oportunidad de una comprensión de la realidad (199). Esta posibilidad de entendimiento intenta remediar la alienación del sujeto dentro de la realidad globalizadora de la sociedad posmoderna, habitada

10 No creo que sea casual el hecho que parte del desenlace de la novela de Vázquez Montalbán tome lugar en Port Bou, la frontera entre España y Francia, donde está enterrado Benjamin. Irónicamente, la aparente osificación del pasado en el ambiente estático, incambiable, del cementerio recalca el sentido de la "presencia del ahora” que describe Pensky.

Revista Iberoamericana, Vol. LXXVI, Núm. 231, Abril-Junio 2010, 459-475 ISSN 2154-4794 (Electrónico)
ISSN 0034-9631 (Impreso) 
tanto por el detective como por sus lectores. En El hombre de mi vida, sin embargo, el detective es incapaz de explicar esta realidad y mucho menos de encontrar la "bisagra que unía su imaginario de Barcelona" con las nuevas construcciones que dominan ciertas zonas de la ciudad y donde se han perdido las huellas de su pasado proletario (Vázquez Montalbán 44). Ante este escenario, el detective se pregunta, “¿[p]or qué recordaba tanto la infancia últimamente?” (47). Esta insistencia en el pasado y su memoria se materializa en el reencuentro entre Carvalho y Yes, así como en el dolor de una pérdida cuyo reconocimiento traza el melancólico recorrido urbano de estos personajes.

Los contornos de una similar dolencia se perfilan en la novela de Padura ,donde Mario Conde, en su investigación para resolver un asesinato, tropieza con un pedazo del pasado que no puede, para su sorpresa, dejar de indagar. El misterioso artículo que aparece entre las hojas del imposible libro de recetas para la realidad cubana (los tomos de la historia cultural de este país) obliga a Conde a iniciar la búsqueda de una antigua cantante de boleros cuyo fantasma parece haber tomado posesión de su pensamiento. Su búsqueda, alentada y atraída al mismo tiempo por una antigua grabación de su canción más conocida, "Vete de mí,” lo lleva a recorrer un paisaje urbano donde la evocación del pasado sólo sirve para demarcar el paso de una ilusión inexistente y sus espectros. ${ }^{11}$ Visitando la zona de la vida nocturna donde había actuado una vez Violeta del Río, el ex policía se encuentra con un renovado Vedado, surgido después de los años más duros de la crisis cubana, que se despliega con un ritmo y una densidad que no logra atrapar ni reconocer y en cuyas calles Conde siente "por primera vez en sus casi cuarenta y ocho años de vida, que trashumaba por una ciudad desconocida, que no le pertenecía y lo empujaba, excluyéndolo” (La neblina 204). Desde estas calles, todavía en busca de la cantante a quien, según el ex policía, "se la tragó la historia” (202), el Conde emprende el camino hacia el antiguo Mercado Único, donde "sobre el mapa de la ciudad queda palpitando un triángulo eternamente degradado en cuyas entrañas se ha acumulado, a lo largo de los siglos, una parte del desecho humano" (206). Este "territorio cedido" que recorre el personaje es uno de los barrios más pobres y olvidados de La Habana, cuya subsistencia marginal se hace dolorosamente patente durante la búsqueda de la cantante. Ante el peligro, el abandono, el crimen que marca la identidad de este espacio abandonado y el rediseño excluyente del Vedado en “una geografía urbana, estratificada según los dólares poseídos” (203), se contrapone el recuerdo que trae consigo la figura de la cantante y el ambiente cultural del pasado al cual había pertenecido. La irrupción del paisaje cultural de la Cuba prerevolucionaria provoca una nostalgia contagiosa. Al medir las deficiencias

${ }^{11}$ El título de la novela también proviene de la letra de la canción.

Revista Iberoamericana, Vol. LXXVI, Núm. 231, Abril-Junio 2010, 459-475
ISSN 2154-4794 (Electrónico) 
del presente, esta nostalgia, que no está únicamente relacionada a la desaparición de esta cantante y menos a una forma de vida que impone una visión idealizada del pasado, se convierte en una agresividad que invade la experiencia diaria del ex policía y la de sus íntimos amigos. Así, cada mirada, cada reflexión cotidiana o alusión a lo ya acontecido, ya sea de manera casual o intencionada, se convierte en una constante reiteración de algo que se ha perdido, de algo que ya ha dejado de existir. Esta ausencia, asimismo, se materializa en un estado de melancolía que mantiene viva la referencia al pasado.

El estado afectivo que une las dos investigaciones, de El hombre y de $L a$ neblina, desvela, sobre todo, una compleja relación con el pasado, cuyos rastros provocan repercusiones traumáticas en la memoria individual y que no pueden dejar de reconocerse en el presente. Es en este trauma imposible de escapar donde hay que reconocer la melancolía que impregna la mirada hacia el pasado de Carvalho y Conde, y que puede entenderse como una contemplación obsesiva que se resiste a renunciar a una experiencia histórica. En el caso del ex policía, él mismo reconoce que el mundo de la cantante es un recuerdo casi extinguido, que se había ido "sin dejar otra referencia que los restos físicos de escenarios cerrados, quemados o inaccesibles, incluso para la memoria de alguien empecinado en oponerse al último olvido" (Padura, La neblina 204). Esta oposición lo acaba convirtiendo en un sujeto excluido,

un fantasma del pasado, un ejemplar en galopante peligro de extinción, colocado aquella noche de extravíos ante la evidencia del fracaso genético que encarnaban él mismo y su brutal desubicación entre un mundo difuminado y otro en descomposición. (205)

El desvanecimiento de un mundo y la presciencia existente sobre la desintegración de otro enfatiza un sentimiento de pérdida que se intenta articular en esta resistencia por superar el pasado y que, paradójicamente, marca a la misma vez la necesidad de un planteamiento para el futuro.

David Eng y David Kazanjian explican el interés del concepto de pérdida y el papel crítico que cumple la melancolía, en su colección de ensayos Loss, destacando su capacidad significativa, que abarca tanto la pérdida personal como la colectiva, la espiritual y la material, la psíquica y la social, así como la estética y la política (3). Para estos autores, la pérdida, y también la melancolía, puede entenderse como un concepto dialéctico que establece una relación con el pasado que, si por un lado articula una ausencia, por otro, forzosamente contabiliza aquello que permanece. Es más, aquello que se pierde solamente se conoce por lo que subsiste, y la atención a la manera en que estos restos se producen, se leen y se mantienen "generates a politics of mourning that might be active rather than reactive, prescient rather than

Revista Iberoamericana, Vol. LXXVI, Núm. 231, Abril-Junio 2010, 459-475
ISSN 2154-4794 (Electrónico) 
nostalgic, abundant rather than lacking, social rather than solipsistic, militant rather than reactionary" (2). Dentro de este "politics of mourning" que traza el concepto de la pérdida, se reconoce la capacidad crítica de la melancolía. Partiendo de la definición de Freud sobre la melancolía -que, a diferencia del duelo, representa la incapacidad de superar una pérdida- los autores se enfocan en la obsesión por un acontecimiento anterior para formular un método de interpretación que transforma la carencia en un proceso creativo. Así, la melancolía representa un estado de continuidad que resulta importante porque revela el pasado como algo no resuelto o acabado..$^{12}$ Desde esta perspectiva, este pasado continúa viviendo, existiendo en el presente, y la constante lucha con la pérdida permite, como había sugerido Benjamin, una relación continua y abierta con el pasado, trayendo sus fantasmas y espectros, sus imágenes llameantes y fugaces al presente (4). Lo que proponen Eng y Kazanjian es considerar el concepto de melancolía de Freud no simplemente como una fijación de la pérdida de un objeto pasado, sino como una perseverante relación con esta carencia y sus residuos, que, en esta insistencia, es capaz de generar lugares de memoria e historia, tanto para la reescritura del pasado como para la reimaginación del futuro: "While mourning abandons lost objects by laying their histories to rest, melancholia's continued and open relation to the past finally allows us to gain new perspectives on and new understanding of lost objects” (Eng y Kazanjian 4).

Mediada por la melancolía, la insistencia fantasmal del pasado, inesperable de sus exigencias y sorpresiva en sus manifestaciones, se presenta de esta manera como una nueva forma de indagar el pasado y recuperar sus experiencias a través de la noción de sus deficiencias. Como había formulado Walter Benjamin, el pasado no implica reconocerlo tal como ha sido en su totalidad, sino aprehenderlo como el fulgor de una imagen, "to seize hold of a memory as it flashes up at a moment of danger" (255). La posibilidad de esta comprensión queda condicionada por la persistente relación que existe entre el presente y el pasado que, para Eng y Kazanjian, queda terciada por la melancolía que evita una mirada historicista que tiende a revivir el pasado como algo fijo - "to create fixed and totalizing narratives from those fleeting images”- y, así, es posible mantener una relación abierta con él (1-2). En esta relación, la melancolía no sólo se lee como una condición que posibilita la subjetividad, sino que permite explorar las numerosas prácticas en las cuales "loss is melancholically materialized in the social and the cultural realms and in the political and the aesthetic domains" y que, al final, obliga al pasado

12 En la lectura que hacen de Freud, los autores rechazan la idea de que el psicoanalista haya definido y limitado categóricamente la melancolía como estado patológico (3-4). Lo que dice Freud en su trabajo "Mourning and Melancholia" es que no hay suficiente material empírico para finalizar sus observaciones sobre la melancolía (587).

Revista Iberoamericana, Vol. LXXVI, Núm. 231, Abril-Junio 2010, 459-475
ISSN 2154-4794 (Electrónico) 
"to bear witness to the present" (Eng y Kazanjian 5).$^{13}$ En el caso de Carvalho y Conde este testimonio del pasado es una operación espacial que, capturada a través de una mirada perspicaz, examina el espacio urbano en busca de pistas que iluminen la realidad más allá de los misterios que surgen de un acto criminal. Es una contemplación que es capaz de recuperar y capturar en el espacio del presente aquello que no es visible sino por sus rastros, aquello que Benjamin reconocería como sus ruinas y de las cuales surgen los destellos que guardan su conocimiento. Para éste, el peligro que con lleva dicho momento de lucidez es el constante esfuerzo que debemos hacer seguidamente "to wrest tradition away from the conformism that is about to overpower it” (255).

Avery Gordon, desde esta perspectiva, plantea la posibilidad de hacer una lectura de las exclusiones e invisibilidades, hechos fantasmagóricos, que pueden rastrease en el presente porque son, al final, restos de una materialidad que ha existido o sigue existiendo (17). Articulando el concepto de haunting, Gordon busca una particular mediación que describa el proceso de unión entre una institución y un individuo, una estructura social y un sujeto, y una historia con una biografía, de manera que permita la posibilidad de revelar "a form of social figuration that treats as a major problem the reduction of individuals "to a mere sequence of instantaneous experiences which leave no trace [...]”’ (19-20). Estar bajo la sumisión de estos fantasmas y de seguirlos y escribir desde espacios encantados es, antes que nada, tratar de reconstruir la vida donde solamente existe una vaga memoria o una apenas distinguible señal, "about writing ghost stories, stories that not only repair representational mistakes, but also strive to understand the conditions under which a memory was produced in the first place, toward a countermemory, for the future” (Gordon 22). La espacialización del pasado y la recuperación de la memoria y sus rastros encauzados por el estado afectivo de la melancolía obliga, a la misma vez, a plantearse el futuro y a desmarcarse de las deficiencias que presagian la posibilidad de una pérdida ulterior. La aparente superación del pasado desde una lectura parcial del posmodernismo se ve obligada, desde esta lectura espectral, a enfrentarse a la permanencia de los rastros del pasado a pesar del rechazo a la posibilidad de su total representación. Así, el recorrido por el espacio urbano que hacen los protagonistas de las novelas de Vázquez Montalbán y Padura no sólo marca sus pérdidas sino también cierta sensación de impotencia e imposibilidad ante la realidad que los rodea. Pero las ciudades que se perfilan como sitios de dolor y de ausencia ante las cuales sólo es posible el reconocimiento de la realidad y la

${ }^{13}$ Esta posibilidad del subjetivismo se presenta como la alternativa a la visión posmoderna que, cuestionando la capacidad del sujeto individual para introducirse en un conjunto multidimensional de realidades discontinuas y la incapacidad para representar este proceso, articula la noción de la 'muerte del sujeto', su fragmentación o descentración esquizofrénica (Jameson 413). Revista Iberoamericana, Vol. LXXVI, Núm. 231, Abril-Junio 2010, 459-475
ISSN 2154-4794 (Electrónico) 
pérdida de una utopía, también sirven como espacios de "haunting” que insisten en la necesidad de mantener, crear y llenar estos espacios para recuperarlos de los espectros que lo habitan. Como observa Balibrea-Enríquez, si bien la desaparición de la textualización de la utopía puede entenderse como síntoma de la incapacidad de concebirla, de Vázquez Montalbán, y de la izquierda en general, el proceso de la investigación o el método indagatorio de Carvalho no sustituye la utopía sino que protege el espacio desde el cual es posible su nueva concepción (156-57). Aunque la posición irónica así como el cinismo de ambos investigadores se ha relacionado a este espacio y a un aparente distanciamiento del ímpetu utópico del pasado, la melancolía que invade el reconocimiento de este vacío es lo que mantiene, al final, la viabilidad de volver a imaginar la utopía. Aun cuando Conde piensa que el descubrir las verdades sobre la cantante de boleros es una actividad únicamente onanista, al mismo tiempo, no puede dejar de reconocer que es la única manera de rescatar su memoria, desde una posición subjetiva motivada por la melancolía (Padura, La neblina 204).

Volviendo al inicio de nuestra discusión de las novelas de Vázquez Montalbán y Padura en relación a la estética posmoderna y su postura ética, lo que nos interesa es el constante posicionamiento del posmodernismo, sea en cualquiera de sus manifestaciones, dentro de una situación implícita y explícitamente política que revela la naturaleza del capitalismo global de hoy día (Jameson 3). Además de la herramienta crítica que nos provee esta lectura para evaluar la reificación -“the trasformation of social relations into things" o "the effacement of the traces of production"-de los procesos de producción en la sociedad capitalista y posmoderna, lo que nos interesa de ella es la manifestación ética que sigue postulando un claro compromiso político (314). Siguiendo, una vez más, las observaciones de Jameson, la espacialidad de la historia desde la posición posmoderna nos provee una nueva forma de organizar y comprender el espacio social, como se ha ejemplificado a través de las lecturas de El hombre de mi vida y La neblina de ayer. Dentro de esta nueva historiografía espacial, sin embargo, cabe preguntarse qué sentido tiene la política pragmática, enfrentada con la crisis del socialismo internacional, o con las enormes dificultades estratégicas para coordinar acciones políticas de vecindarios a nivel local y de base, ya que lo que esta situación revela es que "the incapacity to map spatially is as crippling to political experience as the analogous incapacity to map spatially is for urban experience" (Jameson 416). Desde esta posición, Jameson sugiere que tal vez la propuesta de una exitosa representación espacial no sea un drama socio-realista del triunfo revolucionario, sino que puede también estar íntimamente escrito en una narrativa de derrota, "which sometimes, even more effectively, causes the whole architectonic of postmodern global space to rise up in ghostly profile behind itself, as some ultimate dialectical barrier or invisible limit"

Revista Iberoamericana, Vol. LXXVI, Núm. 231, Abril-Junio 2010, 459-475
ISSN 2154-4794 (Electrónico) 
(415). Esta narrativa, una vez más, insiste en un estado afectivo que es capaz de ensimismarse dentro de esta narrativa y articular sus más íntimas revelaciones. La melancolía que impulsa la actividad indagatoria de las novelas negras de Vázquez

Montalbán y de Padura puede entenderse como ese instrumento desde el cual, una vez trazadas las pérdidas del pasado y su Historia, se posibilita la delineación de una carencia futura que no suplanta ni intenta reemplazar una utopía prescrita como antes, sino que preserva e insiste en la permanencia de su necesidad.

\section{BiBLIOGRAFÍA}

Avelar, Idelber. The Untimely Present. Postdictatorial Latin American Fiction and the Task of Mourning. Durham: Duke UP, 1999.

Balibrea-Enríquez, Mari Paz. "Viaje al fin del mundo: política del tiempo y el espacio en Milenio Carvalho”. Manuel Vázquez Montalbán. El compromiso con la memoria. José f. Colmeiro, ed. Londres: Tamesis Books, 2007. 197-210.

Benjamin, Walter. “Theses on the Philosophy of History.” Illuminations. Hannah Arendt, ed. y Harry Zohn, trad. Nueva York: Shocken Books, 1985. 253-64.

Braham, Persephone. Crimes against the State, Crimes against Persons. Detective Fiction in Cuba and Mexico. Minneapolis: U of Minnesota P, 2004.

Chandler, Raymond. The Simple Art of Murder. Nueva York: Vintage Book, 1988.

Colmeiro, José F. La novela policíaca española: teoría e historia crítica. Barcelona: Anthropos, 1994.

Compitello, MalcomAlan. “Spain’s Nueva Novela Negra and the Question of Form”. Monographic Review/Revista Monográfica 3/1-2 (1987): 182-91.

Eng, David y David Kazanjian, eds. Loss. The Politics of Mourning. Los Angeles: U of California P, 2003.

Epple, Juan Armando. “Leonardo Padura Fuentes”. Hispámerica XXIV/71 (1995): 49-66.

Freud, Sigmund. "Mourning and Melancholia”. The Freud Reader. Peter Gay, ed. Nueva York: W.W. Norton \& Company, 1989. 584-89.

Gordon, Avery. Ghostly Matters. Haunting and the Sociological Imagination. Minneapolis: U of Minnesota P, 1997.

Hutcheon, Linda. The Politics of Postmodernism. Nueva York: Routledge, 1989. Jameson, Fredric. Postmodernism or, The Cultural Logic of Late Capitalism. Durham: Duke UP, 1997.

Lefebvre, Henri. The Production of Space. D. Nicholson-Smith, trad. Oxford: Blackwell, 1996.

\footnotetext{
Revista Iberoamericana, Vol. LXXVI, Núm. 231, Abril-Junio 2010, 459-475
ISSN 0034-9631 (Impreso)
} 
Martín Gaite, Carmen. El cuarto de atrás. Barcelona: Ediciones Destino, 1979.

McNeill, Donald. Urban Change and the European Left. Tales from the New Barcelona. Londres: Routledge, 1999.

Menton, Seymour. "La novela de la Revolución Cubana, fase cinco: 1975-1987”. Revista Iberoamericana LVI/152-53 (julio-diciembre 1990): 913-32.

Nichols, William. "A la sombra de la Torre Mapfre: Leyendo la Barcelona del fin del milenio en El hombre de mi vida”. Manuel Vázquez Montalbán. El compromiso con la memoria. José F. Colmeiro, ed. Londres: Tamesis Books, 2007. 185-196.

Padura Fuentes, Leonardo. "Reivindicación de la memoria. Entrevista con Manuel Vázquez Montalbán”. Quimera 106-107 (1991): 47-53. Modernidad, posmodernidad y novela policial. La Habana: Ediciones Unión, 2000. La neblina del ayer. Barcelona: Tusquets Editores, 2005. "En Cuba".

Pensky, Mac. Melancholy Dialectics. Walter Benjamin and the Play of Mourning”. Amherst: U of Massachussets P, 2001.

Pérez Miguel, Leandro. 'En Cuba hay un sueño que dejó de existir'. El Mundo (22 septiembre 1998). 16 abril 2001. <http://www.el-mundo.es/1998/09/22/ cultura/22NO100.html>

Schaefer-Rodríguez, Claudia. “On the Waterfront: Realism Meets the Postmodern in Post-Franco Spain’s Novela Negra”. Hispanic Journal 11/1 (1990): 133-46.

Smith, Verity. "A Formula for Hard Times: An Introduction to the Crime Fiction of Leonardo Padura Fuentes and an Interview with the Author”. Hispanic Research Journal 2/1 (February 2001): 61-75.

Soja, Edward W. "Postmodern Geographies and the Critique of Historicism". Postmodern Contentions. Epochs, Politics, Space. John Paul Jones III et. al., eds. Nueva York: The Guilford Press, 1993. 113-36.

Tyras, Georges. Geometrías de la memoria. Conversaciones con Manuel Vázquez Montalbán. Granada: Zoela ediciones, 2003.

Vázquez Montalbán, Manuel. La literatura en la construcción de la ciudad democrática. Barcelona: Letras de Crítica, 1998.

Y Dios entró en La Habana. Madrid: Aguilar, 1998.

El hombre de mi vida. Barcelona: Editorial Planeta, 2000.

ISSN 0034-9631 (Impreso) 
